\title{
PREDICTORS OF LARGE ESOPHAGEAL VARICES IN CIRRHOTIC PATIENTS PRESENTING TO A TERTIARY CARE CENTRE IN SOUTH INDIA
}

\author{
P. Anita ${ }^{1}$, D. Rahul2, Kondadasula Panduranga Rao 3, B. Prabhakar ${ }^{4}$, B. Ramesh Kumar 5 , K. Ravikanth', Mohd. Saad Uddin Azmi ${ }^{7}$, \\ P. Vivek Sagar ${ }^{8}$
}

${ }_{1}^{1}$ Post Graduate, Department of Gastroenterology, Osmania Medical College and General Hospital. ${ }^{2}$ Post Graduate, Department of Gastroenterology, Osmania Medical College and General Hospital. ${ }^{3}$ Professor and HOD, Department of Gastroenterology, Osmania Medical College and General Hospital. ${ }^{4}$ Professor, Department of Gastroenterology, Osmania Medical College and General Hospital. ${ }^{5}$ Associate Professor, Department of Gastroenterology, Osmania Medical College and General Hospital. ${ }^{6}$ Post Graduate, Department of Gastroenterology, Osmania Medical College and General Hospital.

${ }^{7}$ Post Graduate, Department of Gastroenterology, Osmania Medical College and General Hospital.

${ }^{8}$ Post Graduate, Department of Gastroenterology, Osmania Medical College and General Hospital.

\section{ABSTRACT}

\section{BACKGROUND}

Variceal bleeding is a major cause of morbidity and mortality in cirrhosis and endoscopic examination is not accessible in most rural centers. The aim of the study is to identify the clinical, hematological, biochemical, and ultrasonographic parameters that predict the presence of large esophageal varices in patients with cirrhosis.

\section{METHODOLOGY}

Seventy two patients fulfilling inclusion criteria were enrolled for this prospective observational study. Relevant clinical parameters like ascites, splenomegaly, jaundice and laboratory parameters like complete blood picture with absolute platelet count, prothrombin time, serum bilirubin, albumin, CTP class and ultrasonographic characteristics like spleen size, splenic vein size, portal vein diameter were recorded and assessed. Univariate and multivariate analysis was done for predictors of large esophageal varices.

\section{RESULTS}

Thirty one (43\%) patients in this study had varices, out of them $15(48 \%)$ had large varices. On multivariate analysis, presence of large esophageal varices was significantly associated with a spleen size $>16 \mathrm{~cm}$ ( $\mathrm{p}$ value-0.001), platelet count $<88,000$ (p value0.003) and CTP Class B/C ( $\mathrm{p}$ value-0.02).

\section{CONCLUSIONS}

Thrombocytopenia $<88,000$, splenomegaly $>16 \mathrm{~cm}$ and CTP class B and C can stongly predict the presence of large esophageal varices. PLC/SD ratio, SAAG, PVD and PVF did not have any statistical significance in predicting large esophageal varices in our study.

\section{KEYWORDS}

Large varices, CTP class B/C, Thrombocytopenia, Splenomegaly.

HOW TO CITE THIS ARTICLE: P. Anita, D. Rahul, Kondadasula Panduranga Rao, B. Prabhakar, B. Ramesh Kumar, K. Ravikanth, Mohd. Saad Uddin Azmi, P. Vivek Sagar. "Predictors of Large Esophageal Varices in Cirrhotic Patients Presenting to a Tertiary Care Centre in South India." Journal of Evolution of Medical and Dental Sciences 2015; Vol. 4, Issue 96, November 30;

Page: 16155-16159, DOI: 10.14260/jemds/2015/2370

\section{INTRODUCTION}

Variceal bleeding is a medical emergency associated with a mortality that in spite of recent progress, is still in the order of $10-20 \%$ at 6 weeks. ${ }^{1}$ The prevalence of varices is approximately $60-80 \%$ and the risk of bleeding is $25-35 \%$ in patients with cirrhosis. Progression from small-to-large varices is approximately at a rate of 5 to $10 \%$ per year. ${ }^{2}$ Primary prophylaxis with either nonselective beta-blockers or endoscopic band ligation may reduce the risk of variceal bleeding. ${ }^{2}$

Financial or Other, Competing Interest: None.

Submission 14-11-2015, Peer Review 16-11-2015,

Acceptance 23-11-2015, Published 27-11-2015.

Corresponding Author:

D. Rahul,

H. No. 613, Pragathi Nagar

Opp. JNTU, Nizampet Post,

Kukatpally, Hyderabad-500090,

Telangana.

E-mail: dubbakarahul@yahoo.com

DOI:10.14260/jemds/2015/2370
Baveno VI Consensus Conference on portal hypertension recommended that all cirrhotic patients should be screened for the presence of esophageal varices, when liver cirrhosis is diagnosed. ${ }^{1}$ As a result of invasive nature of endoscopy and unavailability in rural settings developing a non-invasive predictor of the presence of large varices would help in selective referral of patients and starting primary prophylaxis to prevent variceal haemorrhage. Several prediction models with a combination of platelet count, ChildPugh class, platelet count, splenomegaly, spleen width and portal vein diameter were investigated in a number of studies to predict the presence of varices. However, different studies have yielded different results probably due to differences in the population selected.

\section{METHODOLOGY AND PATIENT SELECTION}

This prospective observational study was performed between March 2010 and August 2011 at Department of Gastroenterology, Osmania General Hospital. All patients with cirrhosis of liver presenting to the Department of Gastroenterology and General Medicine, who did not undergo endoscopy previously were included. Patients with prior 
treatment with $\beta$-blockers or endoscopic variceal ligation or endoscopic sclerotherapy, upper gastrointestinal hemorrhage before endoscopy, history of TIPS or Shunt surgery, patients with only gastric varices and patients with HCC were excluded from this study.

Detailed history and symptoms and signs of cirrhosis were recorded in all patients. Ascites was graded as Grade I (Mild ascites only detectable by ultrasound), Grade II (Moderate ascites evident by moderate symmetrical distension of abdomen) or Grade III (Large or gross ascites with marked abdominal distension). ${ }^{3}$ Hepatic encephalopathy was graded from grade 0 to IV as per the Conn's grading. ${ }^{4}$ Diagnosis of cirrhosis was based on clinical biochemical, and imaging findings.

\section{BLOOD INVESTIGATIONS}

Complete blood picture with haemoglobin, total leukocyte count, platelet count, liver function tests, serum bilirubin (Total and conjugated), alanine aminotransferase and aspartate aminotransferase, protein, albumin, INR prothrombin time were done. Child-Pugh score was calculated for each patient. ${ }^{5}$ Viral markers for HBsAg and antibodies to hepatitis $\mathrm{C}$ virus were done to determine the cause of cirrhosis. Other investigations like (Serum ceruloplasmin and slit lamp examination for Wilson's disease, tests for autoantibodies for autoimmune liver disease, iron studies for hemochromatosis) were carried out wherever indicated.

\section{ULTRASOUND ABDOMEN WITH DOPPLER}

Ultrasonography was done in all patients and the maximum vertical span of the liver, nodularity of liver surface, spleen size (Length of its longest axis), diameter of the portal and splenic veins, presence of portal-systemic collaterals, and presence of ascites were recorded.

\section{ENDOSCOPIC EVALUATION}

All patients underwent endoscopy for assessment of esophageal and gastric varices within 1-2 days of admission. Esophageal varices were graded as small $<5 \mathrm{~mm}$ or large $>5 \mathrm{~mm} .{ }^{6}$ Gastric varices, portal hypertensive gastropathy, duodenopathy and rectal varices were recorded wherever present.

\section{STATISTICAL ANALYSIS}

Data was analysed using statistical package for social sciences [SPSS; Version 13, Chicago Inc]. Univariate analysis for determining the association of various clinical, laboratory and ultrasound variables with the presence of esophageal varices was performed using Student ' $t$ ' test for continuous variables and Chi square tests for categorical variables. Difference was considered statistically significant if the two tailed ' $p$ ' value was $<0.05$; a value of $<0.01$ was considered highly significant and a value of $>0.05$ was considered insignificant.

All variables found to be significant in univariate analysis were studied using multiple logistic regression analysis to identify independent predictors for the presence of large esophageal varices.

Receiver Operating Characteristic curves [ROC] analysis was performed on the available data set for the parameter that had the best predictive value of the presence of large esophageal varices. Validity of the model was measured by means of the area under receiver operating characteristic curve [AUROC]. A model with an AUROC above 0.7 was considered useful, while an AUROC between 0.8 and 0.9 indicated excellent diagnostic accuracy; larger the area under ROC curve the better the discriminating ability of the variable. Various cut-off values were investigated for the model to determine the optimal values that predict or exclude large esophageal varices.

Sensitivity and specificity of each significant variable was estimated by the ROC curve. Positive and negative predictive values were calculated for each significant variable.

\section{RESULTS}

Seventy two patients fulfilling inclusion criteria were enrolled for this study. Of these patients, 45 [62.5\%] were male; 27 [37.5\%] were female with a mean age of 47 years with a range of 17-71 yrs. [Table 1]. Most common etiology was alcohol [n-27; 37.5\%], followed by hepatitis B [n-13; 18.05\%], hepatitis $C$ [n-7; 9.7\%], combined infection with hepatitis B and C [n-2; 2.7\%], hepatitis B with alcohol [n-5; 6.9\%], hepatitis $C$ with alcohol [n-4; 5.5\%], Wilson's disease [n-5; 6.94\%], Budd Chiari syndrome [n-7; 9.7\%], secondary biliary cirrhosis [n- $2 ; 2.7 \%]$. There were 14 patients in CTP class A; 28 patients in class B; 30 patients in class C. Overall, 31 patients had esophageal varices; 41 had no esophageal varices. In patients with esophageal varices, 15 had large varices and 16 had small varices. In our study, a platelet count of $<100,000$; spleen size of $>14.5 \mathrm{~cm}$; platelet count/spleen diameter ratio $<870$; portal vein diameter $>13 \mathrm{~mm}$; CTP class B/C were the best indicators of varices [Table 2]. These values represent median values and offered the best discrimination value on univariate analysis, variables significantly associated with presence of large varices were CTP class B/C, platelet count, spleen size, SAAG ratio, portal vein diameter and platelet count/spleen diameter ratio. On multivariate analysis, presence of large esophageal varices was significantly associated with a spleen size $>16 \mathrm{~cm}$, platelet count $<88,000$ and CTP class B/C [Table 3].

\section{DISCUSSION}

Endoscopy to detect varices is an invasive procedure and is not readily available in rural settings; hence, non-invasive parameters to detect large esophageal varices which are more likely to bleed are required. Several studies have evaluated possible non-invasive markers of esophageal varices. The aim of the present study is to identify clinical variables, lab parameters and imaging features that correlate with presence of large esophageal varices, so as to selectively refer patients for prophylactic esophageal band ligation.

Our data showed that 8 factors had predictive ability for the presence of esophageal varices on univariate analysis. However, on multivariate analysis only 5 of these 8 variables, namely a platelet count of $<100,000$; spleen size of $>14.5 \mathrm{~cm}$; platelet count/spleen diameter ratio $<870$; portal vein diameter $>13 \mathrm{~mm}$; CTP class B/C were the best indicators of varices. These values represent median values and offered the best discrimination value. Our data showed that 6 factors had predictive ability for the presence of large esophageal varices on univariate analysis. However, on multivariate analysis only 3 of these 6 variables, namely a platelet count of $<88,000$; spleen size of $>16 \mathrm{~cm}$; CTP class B/C were the best indicators of large varices. These values represent median values and offered the best discrimination value.

The two parameters found to have independent predictive ability for large esophageal varices in our study namely, platelet count and splenomegaly have been the most consistently identified predictors of varices in a number of previous studies. Relationship of these two predictors to the presence of large esophageal varices may be explained, in that a palpable spleen as well as a low platelet count are both related to the presence of higher portal pressure. 


\section{PLATELET COUNT}

Moderate thrombocytopenia is frequent in cirrhosis of the liver and in most cases it is well tolerated. The discovery of the lineage-specific cytokine Thrombopoietin (TPO) explains the link between hepatocellular function and thrombopoiesis. TPO is predominantly produced by the liver and constitutively expressed by hepatocytes. In humans, TPO production is dependent on functional liver cell mass and is reduced in cirrhotics. This leads to reduced thrombopoiesis in the bone marrow and consequently to thrombocytopenia in advanced cirrhosis. ${ }^{7}$ We report that the sensitivity of platelet count of $<88,000$ for prediction of large varices is $82 \%$; specificity is $89 \%$; positive predictive value is $78 \%$; negative predictive value is $82 \%$ [Table 4].

In our study, average platelet count of patients with large varices was 88,000 , compared to 100,000 in patients with small varices. This indicates that while thrombocytopenia is an important predictor of any grade of varices, a count less than 88,000 always predicts the presence of large varices. Our study is in accordance to the studies of Chalasani. ${ }^{8}$ [1999; 346 patients; platelet count of $<88,000$ ], Zaman. $^{9}$ [2002; 300 patients; platelet count of $<80,000$ ], Sarwar. ${ }^{10}$ [2005; platelet count of $\left.<88,000\right]$, Cherian. ${ }^{11}$ [2010; platelet count of $<90,000]$, Burton. ${ }^{12}$ [2007; platelet count $<80,000$ ]. Zein. ${ }^{13}$ [2004], Sanyal. ${ }^{14}$ [2006] reported a platelet count of $<150,000$ as an independent predictor for presence of large varices. Garcia-Tsao. ${ }^{15}$ [2005; 180 patients], Pilette. ${ }^{16}$ [1999; 116 patients], Thomopoulos. ${ }^{17}$ [2003; 184 patients], Schepis. ${ }^{18}$ [2001; 143 patients], Madhotra. ${ }^{19}$ [2002; 184 patients], Giannini. ${ }^{20}$ [2003; 265 patients], Ng. ${ }^{21}$ [1999; 92 patients], Bressler. ${ }^{22}$ [2005; 235 patients], reported that low platelet count is an independent risk factor for the presence of large esophageal varices.

\section{SPLEEN SIZE}

Palpable spleen and splenic size $>16 \mathrm{~cm}$ were important predictors of large varices in our study. We report that a spleen size of $>16 \mathrm{~cm}$, predicted presence of large varices by a sensitivity of $90 \%$, a specificity of $94 \%$, a positive predictive value of $86 \%$, negative predictive value of $90 \%$.

Our study is in accordance to the studies of Cherian. ${ }^{10}$ [2010; spleen diameter of $>16 \mathrm{~cm}$ ], Sharma and Aggarwal. ${ }^{23}$ [2007, spleen diameter of $\geq 14 \mathrm{~cm}$ ], Hong. ${ }^{24}$ [2011; spleen diameter of $>14.5 \mathrm{~cm}$ ], Saragapani. ${ }^{25}$ [2010; spleen diameter of $>14 \mathrm{~cm}]$, Thomopoulos. ${ }^{16}$ [2003; spleen diameter of $>14.5 \mathrm{~cm}]$.

\section{CTP CLASS B/C}

In our study, a statistically significant correlation was found between CTP classification grades and esophageal varices grade. CTP class B/C were associated with a sensitivity of $80 \%$, specificity of $88 \%$, positive predictive value of $72 \%$, negative predictive value of $84 \%$ for the presence of large esophageal varices. Our study is in accordance with the study of Zaman [2001], who reported that advanced CTP class is an independent risk factor for large varices. He reported that CTP class $\mathrm{B} / \mathrm{C}$ had a 3 -fold increase in the risk of having large varices compared with CTP class $A$. This was further corroborated by the studies of Cherian. ${ }^{10}$ [2010], Cales. ${ }^{26}$ [2004], Giannini. ${ }^{19}$ [2003; 184 patients], Burton. ${ }^{11}$ [2007].

\section{CONCLUSIONS}

Cirrhotic patients with a platelet count of less than 88,000 , are more likely to have large esophageal varices on endoscopy than patients with a platelet count of more than 88,000 . Platelet count has an inverse correlation with the presence of large varices. As the platelet count decreases, prevalence of large esophageal varices increases. Size of spleen has a direct correlation with size of esophageal varices. A spleen size of $>16 \mathrm{~cm}$ was associated with large varices whereas a spleen size of $>14.5 \mathrm{~cm}$ was associated with small esophageal varices. Size of varices was also related to the severity of liver disease. Proportion of patients with large varices was more in Child class B and C compared to Child class A.

\section{REFERENCES}

1. Roberto de Franchis, Baveno VI faculty. Expanding consensus in portal hypertension. Journal of Hepatology Sep 2015;vol. 63:issue 3,743- 752.

2. Amico GD, Morabito A. Noninvasive markers of esophageal varices: Another round, not the last. Hepatology 2004;39:30-4. [PubMed: 14752818].

3. EASL clinical practice guidelines on the management of ascites, spontaneous bacterial peritonitis, and hepatorenal syndrome in cirrhosis. Journal of Hepatology 2010; vol. 53:j397-417.

4. Conn H, Bircher J, Editors. IL: Medi-Ed Press; 1994. Hepatic Encephalopathy Syndrome and Therapies. Bloomington; pp. 1-12.

5. Child C, Turcotte J. Surgery and portal hypertension. In: Child CG, editor. The Liver and Portal Hypertension. PA: Saunders 1964; pp. 50-1.

6. Guadalupe Garcia-Tsao, Arun J. Sanyal, et al. Prevention and Management of Gastroesophageal Varices and Variceal Hemorrhage in Cirrhosis. Am J Gastroenterol 2007;102:2086-2102.

7. Peck-Radosavljevic M. Thrombocytopenia in liver disease. Can J Gastroenterol 2000 Nov; 14 Suppl D:60D66D.

8. Chalasani N, Imperiale TF, Ismail A, Sood G, Carey M, Wilcox CM, et Al. Predictors of large esophageal varices in patients with cirrhosis. Am J Gastroenterol 1999;94:3285-91.

9. Zaman A, Becker T, Lapidus J, et al. Risk factors for the presence of varices in cirrhotic patients without history of variceal hemorrhage. Arch Int Med 2001;161:256470.

10. Sarwar S, Khan AA, Alam A, Butt AK, Shafqat F, Malik K, et al. Non-endoscopic prediction of presence of esophageal varices in cirrhosis. J Coll Physicians Surg Pak 2005;15:528-31.

11. C Cherian, N Deepak, R Ponnuswamy, et al. Non-invasive predictors of esophageal varices. Saudi J of Gastroenterogy, Volume 17; Number 1, January 2011.

12. JR Burton, S Liangpunsakul, J Lapidus, E Giannini, N Chalasani and A Zaman. Validation of a Multivariate Model Predicting Presence and Size of Varices. J Clin Gastroenterol Volume 41; Number 6, July 2007.

13. Zein CO, Lindor KD, Angulo P. Prevalence and predictors of esophageal varices in patients with primary sclerosing cholangitis. Hepatology 2004;39:204-10.

14. R Fontana, A Sanyal, M Ghany, W Lee, J Everhart, and the HALT-C trial group. Factors that determine the development and progression of gastroesophageal varices in patients with Chronic Hepatitis C Gastroenterogy 2010;138:2321-2331.

15. D'Amico, Garcia-Tsao, Escorsell, Cestari R. Diagnosis of portal hypertension. How and when? In: de Franchis R, ed. Portal Hypertension III. Proceedings of the Third Baveno International Consensus Workshop on Definitions, Methodology and Therapeutic Strategies. Oxford: Blackwell Science 2007;36-63.

16. Pilette C, Oberti F, Aube C, et al. Non-invasive diagnosis of esophageal varices in chronic liver diseases. J Hepatol 1999;31:867-73. 
17. Konstantinos C, Thomopoulos, Non-invasive Prediction of Esophageal Varices: Is It Possible? Saudi Journal of Gastroenterology, 2011, Jan- Feb; 17(1): 1-3.

18. Schepis F, Camma'C, Niceforo D, et al. Which patients should undergo endoscopic screening for esophageal varices detection? Hepatology, 2001;33:333-8.

19. Madhotra R, Mulcahy HE, Willner I, et al. Prediction of esophageal varices in patients with cirrhosis. J Clin Gastroenterol 2002;34:81-5.

20. Giannini E, Botta F, Borro P, Risso D, Romagnoli P, Fasoli A, Mele MR, Testa E, Mansi C, Savarino V, Testa R. Platelet count/spleen diameter ratio:proposal and validation of a non-invasive parameter to predict the presence of oesophageal varices in patients with liver cirrhosis. Gut 2003;52:1200-1205.

21. Ng FH, Wong SY, Loo CK, Lam KM, Lai CW, Cheng CS, et al. Prediction of oesophagogastric varices in patients with cirrhosis. J Gastroenterol Hepatol 2009;14:785-90.
22. Bressler B, Pinto R, El-Ashry D, et al. Which patients with primary biliary cirrhosis or primary sclerosing cholangitis should undergo endoscopic screening for oesophageal varices detection? Gut 2005;54:407-10.

23. Sharma SK, Aggarwal R. Prediction of large esophageal varices in patients with cirrhosis of the liver using clinical, laboratory and imaging parameters. J Gastroenterol Hepatol 2007;22:1909-1915.

24. Hong WD, Dong LM, Jiang ZC, et al. Prediction of large esophageal varices in cirrhotic patients using classification and regression tree analysis. Clinics (Sao Paulo) 2011;66:119-124.

25. A Saragapani, C Shanmugam, M Kalyanasundaram, et al. Noninvasive prediction of large esophageal varices in chronic liver disease patients. Saudi J of gastroenterology, Volume 16, Number 1, January 2010.

26. Cales, Desmorat, Vinel, Caucanas, et al. Incidence of large oesophageal varices in patient with cirrhosis: application to prophylaxis of first bleeding. Gut 1990;31:1298-1302.

\begin{tabular}{|c|c|}
\hline Characteristics & Data \\
\hline Total number of patients & 72 \\
\hline Male/female & $45 / 27$ \\
\hline Mean age (yr.) & 47 \\
& {$[$ range,17-71] } \\
\hline Etiology of liver disease & $27[37.5 \%]$ \\
\hline Alcohol & $13[18.05 \%]$ \\
\hline Hepatitis B & $7[9.7 \%]$ \\
\hline Hepatitis C & $5[6.9 \%]$ \\
\hline Hepatitis B/alcohol & $4[5.5 \%]$ \\
\hline Hepatitis C/alcohol & $2[2.7 \%]$ \\
\hline Hepatitis B + C & $5[6.94 \%]$ \\
\hline Wilson's disease & $7[2.7 \%]$ \\
\hline Budd-Chiari syndrome & $2[2.7 \%]$ \\
\hline Secondary biliary cirrhosis & $14[19.4 \%]$ \\
\hline Child-Pugh class & $28[38.9 \%]$ \\
\hline A (5-6) & $30[41.7 \%]$ \\
\hline B (7-9) & $17 \pm 5$ \\
\hline C (10-15) & \\
\hline MELD [mean + SD] & Table 1: Patient Demographics \\
\hline &
\end{tabular}




\begin{tabular}{|c|c|c|c|}
\hline VARIABLE & $\begin{array}{c}\text { VARICES LARGE } \\
{[\mathrm{n}=15]}\end{array}$ & $\begin{array}{c}\text { VARICES SMALL } \\
{[n=16]}\end{array}$ & p VALUE \\
\hline AGE [yr] & $43.73 \pm 7.33$ & $46.50 \pm 9.71$ & NS \\
\hline SEX $[\mathrm{M} / \mathrm{F}]$ & $10 / 5$ & $9 / 7$ & NS \\
\hline ASCITES [CLINICAL][\%] & $80 \%$ & $75 \%$ & NS \\
\hline $\begin{array}{c}\text { PALPABLE } \\
\text { SPLENOMEGALY [\%] }\end{array}$ & $93.33 \%$ & $75 \%$ & 0.001 \\
\hline $\begin{array}{c}\text { HEPATIC } \\
\text { ENCEPHALOPATHY [\%] }\end{array}$ & $26.66 \%$ & $25 \%$ & NS \\
\hline JAUNDICE [\%] & $93.33 \%$ & $87.5 \%$ & NS \\
\hline PALLOR [\%] & $80 \%$ & $76.66 \%$ & NS \\
\hline $\mathrm{Hb}[\mathrm{g} / \mathrm{dl}]$ & $10.24 \pm 1.09$ & $11.06 \pm 1.17$ & NS \\
\hline TOTAL COUNT & $5933 \pm 1312$ & $7062 \pm 1881$ & NS \\
\hline ALBUMIN [mg/dl] & $1.99 \pm 0.092$ & $2.16 \pm 0.47$ & NS \\
\hline BILIRUBIN [mg/dl] & $3.03 \pm 0.445$ & $2.78 \pm 0.96$ & NS \\
\hline AST $[\mathrm{IU} / \mathrm{L}]$ & $45.67 \pm 14.13$ & $38.75 \pm 32.33$ & NS \\
\hline ALT [IU/L] & $23.60 \pm 8.692$ & $27.13 \pm 17.64$ & NS \\
\hline PT [sec] & $19.47 \pm 3.11$ & $18.19 \pm 1.64$ & NS \\
\hline INR & $1.86 \pm 0.37$ & $1.76 \pm 0.22$ & NS \\
\hline VARIABLE & $\begin{array}{c}\text { VARICES LARGE } \\
{[\mathrm{n}=15]}\end{array}$ & $\begin{array}{c}\text { VARICES SMALL } \\
{[\mathrm{n}=16]}\end{array}$ & p VALUE \\
\hline $\begin{array}{l}\text { CREATININE } \\
{[\mathrm{mg} / \mathrm{dl}]}\end{array}$ & $1.35 \pm 0.47$ & $1.09 \pm 0.22$ & NS \\
\hline $\begin{array}{l}\text { PLATELET COUNT } \\
{\left[\mathrm{n} / \mathrm{mm}^{3}\right]}\end{array}$ & $88200 \pm 18590$ & $102312 \pm 268529$ & 0.003 \\
\hline PLC/SD RATIO & $559.12 \pm 127.77$ & $713.56 \pm 208.98$ & 0.04 \\
\hline SAAG & $1.74 \pm 0.16$ & $1.15 \pm 0.59$ & 0.001 \\
\hline PVD [in mm] & $15.14 \pm 0.86$ & $12.09 \pm 1.10$ & 0.005 \\
\hline PVF & & & \\
\hline $\mathrm{HP}$ & $33.33 \%$ & $25 \%$ & \\
\hline $\mathrm{HF}$ & $60 \%$ & $68.75 \%$ & NS \\
\hline OBS & $6.66 \%$ & $6.25 \%$ & \\
\hline COLLATERALS & $43.9 \%$ & $57.51 \%$ & NS \\
\hline USG ASCITES & $69.02 \%$ & $87.06 \%$ & NS \\
\hline $\begin{array}{l}\text { USG SPLENOMEGALY } \\
{[\text { in } \mathrm{cm}]}\end{array}$ & $15.89 \pm 4.04$ & $13.89 \pm 1.48$ & 0.001 \\
\hline MELD & $19.87 \pm 4.24$ & $17.13 \pm 3.05$ & NS \\
\hline CTP CLASS & & & \\
\hline A & 0 & 3 [18.75\%] & \\
\hline B & $2[13.33 \%]$ & $7[43.75 \%]$ & 0.001 \\
\hline $\mathrm{C}$ & $13[86.66 \%]$ & $6[37.5 \%]$ & \\
\hline \multicolumn{4}{|c|}{$\begin{array}{c}\text { Table 2: Relationship of Various Parameters with Presence or Absence of Large } \\
\text { Esophageal Varices on Univariate Analysis }\end{array}$} \\
\hline
\end{tabular}

Data presented as mean \pm SD or n [\%]; NS-not significant. PV-portal vein diameter; Portal vein flow; HP-hepatopetal; HFhepatofugal; OBS-thrombosis.

\begin{tabular}{|l|c|c|c|c|}
\hline \multicolumn{1}{|c|}{ VARIABLE } & B & SE & OR [95\% CI] & P \\
\hline 1.SPLEEN SIZE [>16cm] & 1.834 & 0.423 & $3.028[1.61-5.72]$ & 0.001 \\
\hline 2. CTP CLASS B/C & & 1.711 & $3.64[2.21-6.41]$ & 0.02 \\
\hline 3.PLATELET COUNT [< 88000] & 0.554 & 0.7561 & $2.49[1.37-5.12]$ & 0.003 \\
\hline Table 3: Multivariate Logistic Regression Analysis Showing Independent \\
Predictors of Large Esophageal Varices
\end{tabular}

\begin{tabular}{|c|c|c|c|c|c|}
\hline VARIABLE & BEST CUT-OFF & SENS [\%] & SPEC [\%] & PPV & NPV \\
\hline 1.PLC & $<88000$ & 82 & 89 & 78 & 82 \\
\hline 2.SPLEEN SIZE & $>16 \mathrm{~cm}$ & 90 & 94 & 86 & 90 \\
\hline 3.CTP CLASS & B/C & 80 & 88 & 72 & 8 \\
\hline \multicolumn{5}{|c|}{ Table 4: Results of ROC Curve } \\
\hline
\end{tabular}

